\section{Doctor-Patient Relationship}

The practice of medicine is an art not a trade; a calling not a business, a calling in which your heart will be exercised equally with your head.

There are four domains for the professionalism in action for a doctor: Domain 1: knowledge, skills and performance; Domain 2: safety and quality; Domain 3: communication, partnership and teamwork; Domain 4: maintaining trust. It could be done with maintaining 7 principles: 1. maintaining trust, 2 . to do what is most important, 3. to give most to those whose need is the greatest, 4. to use words that are health-promoting, 5. to invest in continuing and supplementary education, research and professional development, 6 . to describe experiences of practice and 7. to take leadership.

\section{The physician and the patient}

Physician is equipped with 1 . scientific knowledge 2 . technical skill 3. human understanding; a) sympathy b) empathy 3) tact.

Patient on the other hand is a 1. Human being; has 2 . collection of symptom and signs; have 3. disordered function. He is a) fearful, but b) hopeful and c) seeking relief, and need d) help and reassurance.

\section{Aim of practice}

Treat and prevent diseases which remain in heart of patient care and depend on intimate relationship between physician and the patients. Practice of medicine is an art and a science as well. It is earned through years of experience. It is a science because it is an applied technology for clinical problem solution. It is the use of advanced biochemistry, cell biology, genomics, imaging modalities .It is the use of latest therapeutic modalities with huge areas of research. It is an art because of the elements in complex history and physical examination and because of the intuition needing experience and judgments with good application of mutual Knowledge, trust and loyalty.

\section{Doctor patient relationship: there are three elements}

a) Emotional: To feel the distress of the patient and cordially eradicate the disease from the root.

b) Cultural: Understand the cultural background c) Intellectual: Most of our patients comes from the relatively poor family, obviously there remains an intellectual gap; a good practitioner needs to overcome the difference

\section{History of doctor patient relationship}

Historical setting depends on a) medical situation (selfreflection, communication and technical skills) b) social scene (socio-political and scientific climate).

Basic models of doctor-patient relationship

\section{Szasz and Hullender}

1. Doctor centered; a) active-passive model guidance b) co-operation model

2. Patient centered; c) mutual participation model.

1. Active-passive model: oldest one: physician acting upon the patient; patient treated as inanimate object.

2. Guidance co-operation model: doctor in position of power, doctor decides, patient complies.

3. Mutual participation model: equal partnership and patient expert on his life experiences/suffering, doctor elicits patient's goal and help to achieve it, both parties with equal power and mutually interdepended with equal satisfaction.

Doctor-patient relationship: evolution of history Ancient Egypt (4000 to 1000 B.C) 2. Greek enlightenment (600 to 100 B.C) 3. Medieval Europe and the inquisition (1200 to 1600 A.D) 4. The French revolution (late $18^{\text {th }}$ century)and 5. Doctor-patient relationship 1700 -to present day.

\section{Ancient Egypt}

The Egyptians were the first to develop the profession of medicine. It was a) priest-supplicant relationship b) magic and mysticism; theology was in core c) healers were as much magicians and priests as they were doctors d) magic was an integral part of care e) psychiatric disorders which were regarded as internal f) activitypassivity type.

\section{Greek enlightenment ( $5^{\text {th }}$ Century B.C.)}

First nation to evolve towards a democratic form of social organization. They introduced 1.a) "Code of 
ethics" for the doctor b) The Hippocratic oath c) 'Bill of rights' for the patient 2.a) Empirical-rational approach e) Naturalistic observation f) Practical trial and error experience, g) Abandoning magical and religious h) Justifications of human bodily dysfunction 2.b) Guidance-co-operation and to a lesser degree mutualparticipation.

\section{Medieval Europe and the inquisition}

It is the history of deterioration, weakening and regression of the doctor patient relationship. It is an activity-passivity model with an effort to restoration of religious, supernatural and magico-religious believes. In it doctor are filled with magical powers, glorious with high ranking position in society. Patients are regarded as helpless and like infants.

\section{The French revolution}

Dominant socio-political events renaissance: it was for liberalism, equality, dignity and science. Here successful protestant protests against mighty Roman Catholic Church. There was removal of English dominance from America. It was the end of an era of discrimination of mentally ill and socially under privileged. Actually it was an activity-passivity approach to a guidance-cooperation model.

\section{0 to present day}

$18^{\text {th }}$ century: Symptom based treatment-patient dominance. Doctors were few in number and patients mainly upper class and aristocratic. An era of competition for dominance (patients vs. doctors and doctors vs. doctors).

Late 18th Century: Mostly active-passive model. Hospitals emerged in this era -which became cornerstone of medical care, knowledge and skills started treating underprivileged; it introduced biomedical model of illness-focused accurate diagnosis and pathological lesion with symptom-the indicator for the presence/ absence of a particular pathology.

Origin of medicine in Indian subcontinent

There was an evolution from ancient Indian medicine to Indian medicine in medieval times of Indian medicine during the $19^{\text {th }}$ century and the first half of the $20^{\text {th }}$ century. There was a progress after independence in the last part of $20^{\text {th }}$ century and $1^{\text {st }}$ part $21^{\text {st }}$ century.

Ancient Indian medicine: writings of the two great stages of Indian medicine, Sushruta, the surgeon and Charaka, the physician.
Indian medicine in medieval times: admixture of Indian medicine with Muslim (Arabian-Persian-Turkish).

Indian medicine during the $19^{\text {th }}$ century and the first half of the $21^{\text {st }}$ century: introduction of modern western system of medicine-British rule doct-higheors were at the highest level of respect in the society

Progress after independence: increased number of health institute and doctor population ratio. MBBS doctor (having proper knowledge of medicine) was the backbone for delivering health services in the rural area.

Last part of 2000 and first part of $21^{\text {st }}$ century: Rapid development in public and private medical sectors, excellent development in the laboratory technology and diagnostic services. So is the specialist and super specialist dominating health care sector.

Doctor-patient relationship in the past in Indian subcontinent

\section{Characteristics}

Ancient India: Practitioners had the highest level of respect in the society.Medicine practice was social and humanitarian vs. business. In $20^{\text {th }}$ century maximum doctors were general physician or family physician. Maximum were practicing in rural, hardly few specialist available in urban. Comprehensive care by local physician/family physicians. They were available round the clock and of low cost. That was health and there was interpersonal-family relationship. Patients hardly believed that doctor could do any harm to the patient or if any unwanted condition aroused then patient thought that it was only God's will. Referral to specialists were absent.

Mismatched relationship between doctor and patients: There is violence throughout the year in Bangladesh. There are various factors behind mismatched relationship like 1 . inequality in health care delivery 2 . rapid technical tevelopment 3 . inadequate doctor patient ratio 4. increased expectation on doctor and health care system 5. rapid expansion of the middle class 6. patient/attendants desire to be a part of decision making 7. expansion of literacy and awareness 8. easy accessibility to information and globalization 9 . corruption in health care system 10. socio-political situation and 11. role of media. ${ }^{1}$

\section{Mismatched relationship}

1) In equality in health care delivery: Government commitment - equal health care to all but there 
remains disparity in private vs public, poor vs rich. There are different financial background and different treatment outcome. So, all anger goes to easy accessible group (doctors).

2) Technical development: there is advancement in medical science, increased in patients' perception to save life/cure and creation of difference between expectation and ground reality. Fact is, early and accurate detection is not always possible and also do not guarantee $100 \%$ survival.

3) Inadequate doctor patient ratio: WHO standard is for every 1400 you need one doctor. We had in Bangladesh, 1 for 10740 in 1993 and 12,690 in 2015. There is less doctor and less time of attendance.

4) Increased expectation on doctor and health care system: There are various reason for this like technical aspect of care, patients satisfactions, cost of care, lack of infra-structural facilities and off course non-availability of treatment care modalities like public hospitals.

5) Rapid expansion of the middle class: The middle class is acquiring the purchasing power, affordability, due to an increase in disposable income; so they expect higher amount for saving lives of their beloved, best possible services (i.e. high probability of survival). Thus poor services or any type of negligence flare-ups the emotion of patients and relatives.

6) Patient's desire to become a part in the decision making process: a) Patients and their relatives want shared decision making. Truth is many of the time correct informed consent is not taken before costly investigation or invasive procedures. To solve we need higher levels of information in hand, to spent time in discussion having longer interview length.

7) Expansion of literacy and awareness: There was low literacy rate, patients had "blind faith". Now high literacy rate increased patient/relatives attitude of asking questions on doctor's unrealistic behavior and as a result the relationship is deteriorating. There is patients/relatives' awareness regarding their rights; so, there is increased litigation.

8) Easy accessibility to information and globalization: "Doctor knows the best" - this blind trust is being replaced by "informed trust". Doctor's perspective here is 'patients are either over smart or problematic', on the other hand, patient perspective is 'smart knowledge from internet and over belief of information gathered'. So-called "e-patient" are educated, high income group, wants more participation, critical about health problems, wants health care at the click of the mouse. Naturally, the doctor is worried about variable and unreliable nature of information in net with loss of human touch.

9) High level of corruption in the health care industry at many levels: at the core is business attitude in specialized care. Added are local, social, political and organizational problems. Annoying tendency to doctor is for opinion both in local and international levels. There is lobbing for care and admission in both public and private sectors, which is un-expected. There is inequality in charges in private vs public, private vs private sector mostly dominated by group interest.

10) Socio-political situation and role of media: Press, television, news portal exploring and producing the facts, the participation in social media by the general public has increased sharply over the past years as well.

\section{Ways to solve}

Apparently there are three levels to recognize and find out the solution. 1. Physician factors 2. Patients' factors and 3. Socio-political and religious factors.

Doctors' factors: may be attributed by explaining with 1. clinical skill 2. communication skill and the most important one 3. patient care skill.

Clininical skill begins with history taking where one is to explore facts of medically significant recent, past and complete family information; whenever feel comfortable. It would help creating unique bondage, helps in viewing illness, highlights patients expectations and confidentiality. Then comes the physical examination, which is an excellent art earned by years of experience, confers a physician the opportunity for communication, reassuring effect creating bondage and rapport. Diagnostic studies always need judicial use. It is to be directed by history and examination and needless to say economic status of the care seeker. 
Patient care skill should be evidence based following the practice guidelines. Medical decision making should take account into medical records with evaluation of possible outcome. It should always take care of specialized group like women, children, elderly and handicapped. One should never forget to identify errors in health care delivery and elucidate grave prognosis and death.

Principles of patient care skill

Evidence based medicine: Clinical decision made considering data derived from prospectively designed randomized controlled clinical trials.

Practice guideline: Guidelines by professional organizations or governmental agencies help in making diagnostic and therapeutic decision. It should be evidence based and cost effective and appropriate to particular patient and clinical situations. May give an useful framework for patient management as well as patients, clinicians and care giver protection.

Limitations: Practice guideline is not unique because of over simplification of complexities of medicine, different and divergent recommendations from different groups with different prospective. It do not account for the uniqueness of each individual and illness.

\section{How to improve patient care Skill?}

To solve this limitation we should follow useful recommendation into clinical practice and we should have real situation approach: we should try to identify errors in health care system like adverse drug reactions and multidrug in critical case. We need to implement recommended safety profile health worker/patient. At the time of approach to grave prognosis and death cases, let us try to be very honest. There should be open communication with patient/elatives. Arrangement may be made for emotional, physical, spiritual supports and needless to say one should always consider religious beliefs.

Communication skill: Transferring ideas and knowledge through messages by physician and feedback from patients is the best way. Effective communication has 3 elements 1. Emotional plane 2. Cultural plane 3. Intellectual plane. There should be in incorporation of humanities, ethics, social context of illness. One should have practical training to experience in communication and facing conflict resolution. ${ }^{1}$
Limitation in patients' perspectives: Three things in our real life scenario arises a) Mental makeup: have accentuation with religion, culture, good beliefs and practical education. He or she should have access to information, financial arrangement and peer information. b) Arogency: never care how much doctor/ specialist know, how much doctor/specialist care. c) Real life situation (unavoidable sometimes): suspicious expensive investigations/medications and long waits for short appointments.

Limitation in hospital/corporate perspective: a) Practical thinking of the hospital/corporate may be different. They want benefit from number of patients seen, investigations ordered and needless to say drugs prescribed. They may be reluctant to quality of diagnosis, standard of treatment. At the end, they may compromise with overwhelming workload, dehumanization.

\section{How it can be achieved?}

Socio-political-religious perspective - difficult to achieve if intention is otherwise. Hospital related barrier may be solved by 1 . following citizen charter 2 . establishment and dissemination of information 3 . proper communication 3 . honoring ethical ways of referral and transportation of patients.

\section{Conclusion}

Physician is next to God; he or she should have it in their mind and heart. Physician is privileged to serve the human, he should have noble wisdom to benefit to others. Whatever he or she does, should be in the best interest of patients. Mutual knowledge, trust, loyalty and regard are key elements of doctor-patient relationship. Patient centered attitude is the best, establishment of relationship (rapport) is itself therapeutic. Fair decision and proper communication with easy language is the key element. Finally, collaborative care may have better and effective outcome. It should have multiparty contribution. Role of media, professional organizations, patient welfare bodies, governmental agencies, changing corporate attitude could improve the situation. Motto should be "patient does not fail treatment and treatment does not fail to benefit". (adopted from Prof. Nurul Haque gold medal oration by Prof. Firoz Ahmed Quoreshi in the $29^{\text {th }}$ Annual Conference and Scientific Sessions of APB, 2018)

\section{References}

1. Violence against doctors in China: why China? Why now? What nex? Lancet 2014;383:1013. 